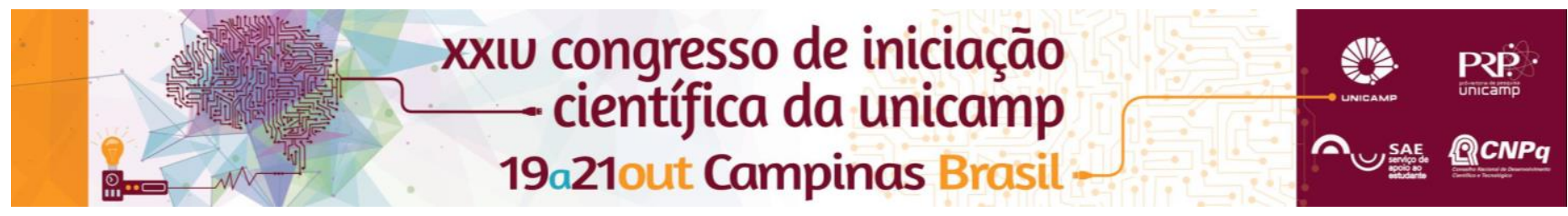

\title{
O bairro como unidade de planejamento em São Paulo e o plano Itaquera - Vila Matilde do Projeto CURA (Comunidade Urbana para Recuperação Acelerada)
}

\author{
Thays Carmonha Damin*, Sidney Piochi Bernardini
}

\begin{abstract}
Resumo
Sob a condução da antiga EMURB (Empresa Municipal de Urbanização) da Prefeitura de São Paulo, o Plano Itaquera Vila Matilde, desenvolvido em 1973 pelo arquiteto Harry James Cole, no âmbito do Programa CURA (Comunidade Urbana de Recuperação Acelerada), foi uma experiência inovadora num período em que os planos desenvolvidos em São Paulo tinham caráter técnico, sistêmico e visavam predominantemente alavancar investimentos relacionados a obras de infraestrutura associadas a oportunidades de desenvolvimento imobiliário. Mesmo que este plano não tenha sido efetivado, ele possui elementos importantes para revelar a introdução da escala do bairro nos processos de planejamento em expansão no período. O objetivo desta pesquisa foi investigar seus pressupostos e conteúdos, analisando criticamente a filosofia, as propostas e a posterior alteração que ele sofreu. Utilizando-se do método historiográfico, que incluiu a interpretação e análise de documentos primários, como o próprio Plano, seus mapas e relatórios subsequentes, foi possível esclarecer e revelar, em termos espaciais, os conceitos e modelos trazidos por Harry James Cole e indicar entraves que a política territorial centralizadora exercia naquele momento.
\end{abstract}

\section{Palavras-chave:}

Programa Cura, Plano Itaquera - Vila Matilde, bairro

\section{Introdução}

As décadas de 1960 e 1970 foram marcadas por um processo de urbanização rápido e precário à revelia das medidas antecipadas de controle e disciplinamento urbanos implementadas pelo Estado. O Programa CURA (Comunidade Urbana de Recuperação Acelerada) nasceu neste cénario e foi criado pelo BNH, em 1973, por meio de um estudo piloto encomendado ao arquiteto Harry James Cole. Tal estudo pretendia detectar as causas da estagnação de áreas urbanas e possíveis soluções que poderiam ser levadas a efeito, constituindose em um modelo teórico para o desenvolvimento do Projeto Piloto do Programa e fornecendo subsídios que viabilizassem uma linha de financiamento. Apesar de ser um Programa de atuação nacional, os planos vinculados ao Programa CURA eram focalizados em melhorias urbanísticas de trechos específicos do território e, muitos deles, eram em bairros consolidados. Entre as ideias centrais que o Programa continha estava a preocupação de torná-lo auto-sustentável, almejando, inclusive, que o município passasse a gerar receita própria. Para isso, realizavam-se estudos de viabilidade a fim de saber em quanto tempo os projetos se pagariam, fazendo uso, inclusive, de forma pioneira, da ferramenta do IPTU Progressivo, para que os proprietários dos terrenos ociosos, após a implementação do plano, fossem induzidos a utilizá-los ou edificá-los, uma vez que chegaria um momento em que o imposto equivaleria ao de um imóvel construído. No caso do Plano Itaquera Vila Matilde, uma área delimitada em bairros de moradores pobres da periferia em expansão da zona leste de São Paulo, o contexto da implementação das linhas de metrô explica sua aprovação no Programa já que, normalmente, ele não se enquadraria no processo de viabilidade financeira.

\section{Resultados e Discussão}

Analisando as propostas do Plano Itaquera - Vila Matilde, fica claro que se buscava atingir uma legibilidade para o bairro e, para solucionar tais aspectos, são usadas ferramentas de zoneamento e de variação de densidade populacional, direcionando a modelagem de uma volumetria mais diversificada. Dentre tais propostas, aquelas que possuíam maior caráter estético e de desenho, são: construção de unidades habitacionais multifamiliares, para garantir a variação tipológica das habitações; criação de "nucleações" de atividades comunitárias, comerciais e de serviço (CRT's), que incluíam núcleos de recreação em praças e uma nucleação industrial num parque ciliar; criação de vias de tráfego limitado com tratamento de espaços de permanência nas calçadas e, por fim, a proposta de dois parques ciliares. Fica claro, portanto, que o Plano Itaquera/Vila Matilde possuía grande qualidade de proposições. Entretanto, não recebeu apoio e confiança dos promotores do empreendimento e, posteriormente, as propostas citadas foram, ou modificadas, ou suprimidas pelas alterações do relatório da COGEP (Coordenadoria Geral de Planejamento) da Prefeitura de São Paulo.

\section{Conclusões}

Ainda que entraves tenham inviabilizado a efetivação do Plano Itaquera - Vila Martilde, o estudo de suas propostas deu insumos para identificarmos elementos importantes na introdução da escala do bairro nos processos de planejamento em expansão no período, compreendendo o potencial do que pode ser feito no aproveitamento deste arranjo territorial e pontuando os obstáculos que a política territorial centralizadora colocava em contraponto aos apoios técnico e financeiro que os municípios recebiam.

\section{Agradecimentos}

Pesquisa realizada com apoio da Fundação de Amparo à Pesquisa do Estado de São Paulo - FAPESP

Lucchese, Maria Cecília. Curam-se cidades: uma postura urbanística da década de 1970. Dissertação de Mestrado. São Paulo, FAU USP. 2004.

H.J. COLE + ASSOCIADOS S.A. - Area CURA Piloto de Itaquera/Vila Matilde. Volumes I,II,III, IV. São Paulo: EMURB, Julho/1974. 